\title{
Incorporating vulnerability of hang-ups and secondary breaking to drawpoints availability for short-term cave plans, El Teniente mine
}

\author{
D Garcés CODELCO, Chile \\ H Rebolledo CODELCO, Chile \\ P Miranda CODELCO, Chile
}

\begin{abstract}
Block and panel caving are increasingly considered as suitable massive underground methods for mining large, deep and competent orebodies. Currently, one of the main challenges in cave mines is the compliance to high daily production rates without putting aside cave management measures. This is a crucial cave concept to incorporate into short-term planning since a lack of cave management may cause significant issues in geomechanics, caving initiation and propagation, cave flow and incorporation rate. This paper focuses on developing a methodology to estimate drawpoint availability uncertainty taking into account hang-up frequency and secondary breaking as key operational variables for short-term planning. Mine data regarding daily draw, hang-ups at drawpoints and secondary breakage activities are gathered from El Teniente mine to determine probability distribution functions of each studied variable. These probability distributions are combined with Monte Carlo simulation for assessing monthly cave productions at the study area. The results obtained herein are of great importance since this method provides a measure of the monthly production compliance. Moreover, the research allows for the identification of drawpoints prone to low availability, in where planned decisions and operational effort may lead to mitigating vulnerabilities of cave production plans.
\end{abstract}

\section{Introduction}

In recent years, block and panel caving methods have been increasingly proposed for the exploitation of deep and massive deposits since they offer relatively high production rates and low operating costs. Traditionally, cave mining relies on the principle of undercutting rock and then letting the gravity to induce the caving process through the ore column. However, even though block and panel caving were initially used for low-strength rock masses that produced fine fragmentation, these methods have been currently applied in strong orebodies that would not easily cave, leading to larger fragmentation than expected (Brzovic et al. 2016). In order to achieve high production rates, there are key aspects that need to be taken into account during production planning. One of these is rock fragmentation resulting from the caving propagation and movement of caved material to the drawpoint. Fragmentation plays a crucial role when defining draw rates as the particle size can generate intermittent flow inside the cave because of hang-up occurrence and the presence of oversize rocks at drawpoints (Laubscher 1994; Chitombo 2010). Hence, incorporating the hang-up frequency and secondary breaking requirement into the assessment of drawpoint availability is fundamental to setting more reliable short-term production plans.

Fragmentation in cave mining comprises primary and secondary fragmentation. The former involves the separation of particles from the cave back primarily controlled by induced stress during propagation, while the latter derives from the reduction in size of caved rocks as they descend through the draw column (Laubscher 1994). Low rates of draw are expected throughout primary fragmentation because of the effect of rock size on the development of hang-ups and the needs of secondary drill and blasting. A hang-up is defined as caved ore obstructing the natural flow of material at drawpoints, resulting in 
temporal production stoppage. To quantify the impact of hang-ups on drawpoint productivity, hangup frequency is considered as a key parameter to assess how this phenomenon influences the available production tonnage of short-term scheduling. Hang-up frequency may be defined as the tonnage drawn between events of hang-ups. Hang-ups and oversize rocks resulting from cave fragmentation are generally dealt with secondary breaking. This process commonly involves the use of either drill and blasting or mobile rock breaker, which implies that the more the secondary breaking requirement, the less the drawpoint availability for drawing ore.

To date, research on the effect of hang-ups and secondary breaking in cave mining has been carried out through operational strategies and model simulation. Ngidi \& Boshoff (2007), Ngidi \& Boshoff (2011), and Ngidi \& Pretorius (2011) analyse the influence of operational strategies such as cave management, estimation of hang-ups frequency and secondary breaking performance on improving production rates at Palabora cave mine. Viera \& Diez (2014) quantify hang-up frequency as a function of the proportion of the column of primary rock drawn at El Teniente mine, providing insight into the relationship between secondary fragmentation and the column of primary rock at drawpoints. In terms of model simulation, Rubio \& Dunbar (2005) and Rubio \& Troncoso (2008) indicate the importance of hang-ups on drawpoint productivity and consider hang-up frequency into a discrete simulation to estimate the maximum potential productivity of a caving operation. Dirkx et al. (2019) include hang-up delays in a stochastic optimisation model for long-term scheduling, showing that the inclusion of hang-up phenomenon firmly improves production rates. Nonetheless, these studies do not take into account hang-up occurrence and secondary breaking as key variables into a short-term planning approach.

This article proposes the incorporation of hang-ups and secondary breaking uncertainty as critical factors in the assessment of drawpoint availability by using a stochastic approach. The impact of drawpoint availability at different ratios of height of primary rock is taken into account in short-term plans and directly underlies drawpoint productivity in cave mining. This method arises as a useful tool to mitigate the significant effects of deviations from planned draw rates and generate reliable short-term plans.

\section{Background at El Teniente mine}

\section{$2.1 \quad$ Study area}

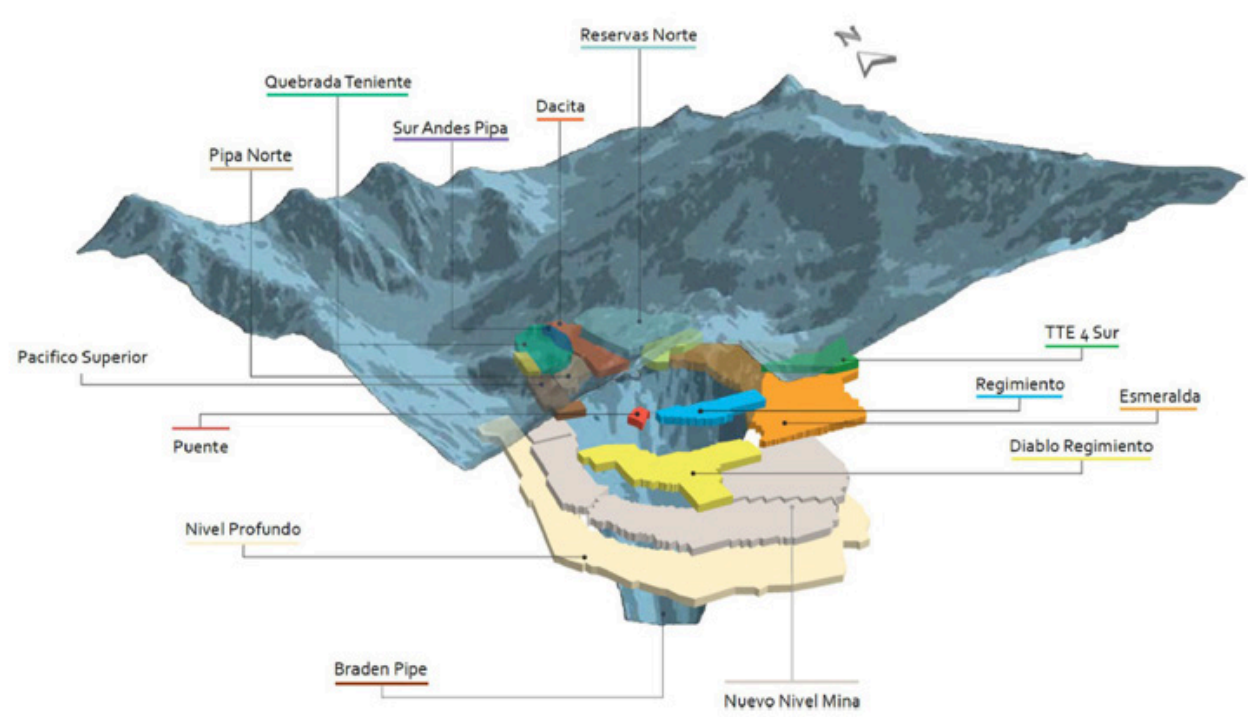

Figure 1 Isometric view of El Teniente mine, indicating the location of the study area

The information was gathered from Diablo Regimiento mine and Esmeralda 's Block-1 and Block-2 cave mines based on the similarity between the rock mass characterization and column of primary rock. These sectors are located around a subvolcanic breccia known as Braden pipe and below abandoned upper mines (Regimiento and TTE 4 Sur, as shown in Figure 1). The study area represents roughly $40 \%$ of the comprised production plan at El Teniente mine (55,000 tons per day). 
The lithology in the study area is a rock mass primarily composed of CMET Fw (EI Teniente Mafic Complex) intruded by tourmaline breccia in the south of Diablo Regimiento mine. CMET Hw and diorite porphyry are present in Block-1 cave, whereas CMET Fw, microdiorite porphyry and tonalite are observed in Block-2 cave. In both mines, the primary in situ rock has been described as competent and massive, with only a few open discontinuities (Brzovic \& Villescusa 2007). Therefore, rock mass preconditioning as hydraulic fracturing was applied to the rock mass, which has been proved to considerably reduce hang-up frequency at drawpoints (Brzovic et al. 2016). The principal physical properties of intact rock and in situ stress conditions of Diablo Regimiento mine and Esmeralda mine are summarized in Table 1. Practically all of these parameters were estimated through experimental test and geotechnical modelling.

Table 1 Geotechnical conditions for each lithological unit within the study area

\begin{tabular}{|c|c|c|c|c|c|}
\hline Lithology & $\begin{array}{c}\text { Uniaxial compressive } \\
\text { strength, UCS (MPa) }\end{array}$ & Density & Porosity (\%) & $\begin{array}{c}\text { Traction strength } \\
\text { (MPa) }\end{array}$ & $\begin{array}{c}\text { Young's } \\
\text { modulus (GPa) }\end{array}$ \\
\hline CMET Hw & 135 & 2.80 & 1.46 & 11 & 57 \\
\hline CMET Fw & 108 & 2.80 & 0.72 & 13 & 50 \\
\hline $\begin{array}{c}\text { Tourmaline } \\
\text { breccia }\end{array}$ & 92 & 2.77 & 2.75 & 9 & 43 \\
\hline $\begin{array}{c}\text { Diorite } \\
\text { porphyry }\end{array}$ & 140 & 2.70 & 2.17 & 12 & 45 \\
\hline $\begin{array}{c}\text { Microdiorite } \\
\text { porphyry }\end{array}$ & 148 & 2.75 & 0.77 & 15 & 49 \\
\hline Tonalite & 162 & 2.72 & 0.71 & 13 & 48 \\
\hline
\end{tabular}

Brzovic \& Schachter (2013) develop a geotechnical zoning of primary rock at El Teniente mine based on the rock mass quality and lineal frequency, P10 (Dershowitz \& Einstein 1988), considering weak veins and fault lineal intensity of the orebody. This geotechnical zone indicates the rock mass cavability for El Teniente mine, as shown in Figure 2.

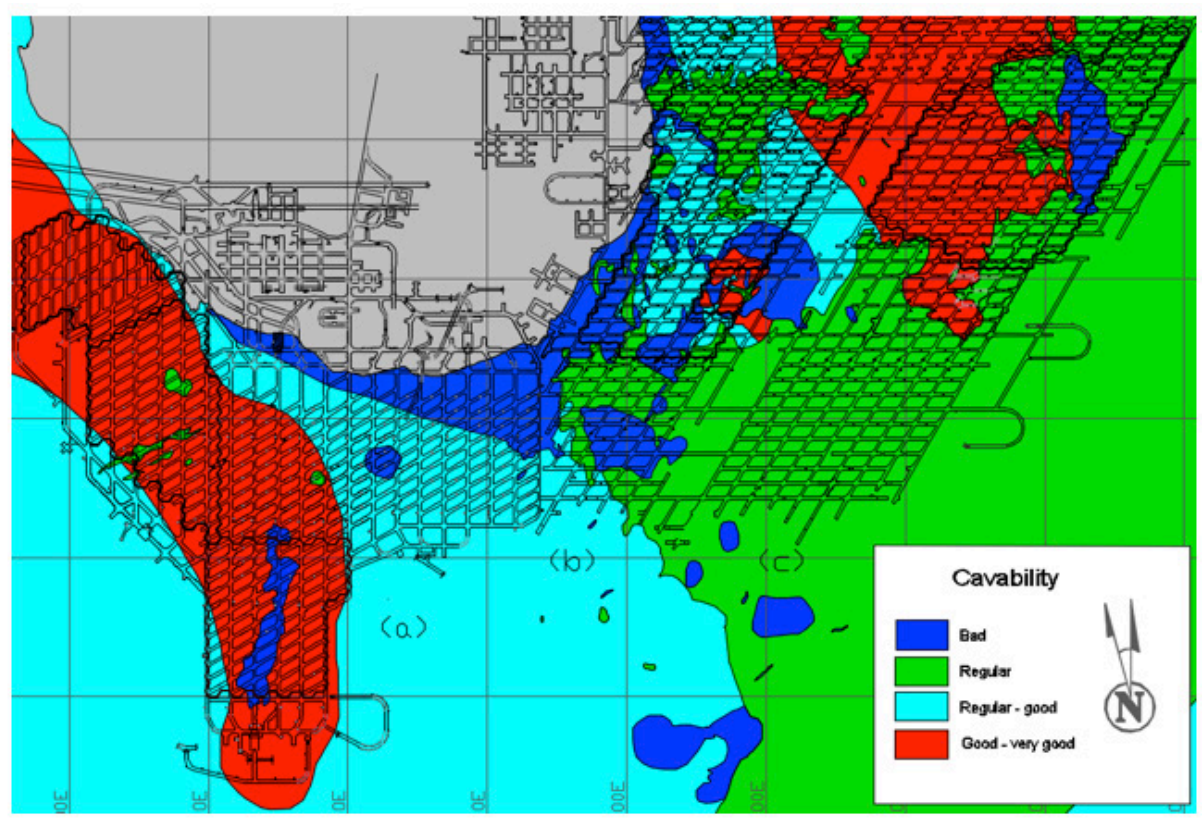

Figure 2 Plan view of geotechnical zones indicating the rock mass cavability expected in the study area. (a) Diablo Regimiento and (b) Esmeralda's Block-1 and (c) Block-2 cave mines (2019)

\subsection{Database}

The data set was built from 242 drawpoints from January to December 2019 whose in situ rock columns are less than $200 \mathrm{~m}$. This is due to there is no clear correlation between draw primary rock column and 
hang-up frequency according to an internal geology report. The database provides information on the type of geotechnical zoning, drawpoint area, height of primary rock (HOPR), ore drawn (in tons), height of draw (HOD), ratio between HOD and HOPR (expressed as percentage), planned draw rates, number of secondary breaking activities and hang-up condition at drawpoints. Note that most of the operating variables are measured per shift (three shifts of 8 hours each). The descriptive statistics of the main variables are described in Table 2.

Table 2 Descriptive statistics for main variables within the database

\begin{tabular}{|c|c|c|c|c|c|}
\hline Variable & Obs & Mean & SD & Minimum & Maximum \\
\hline Drawpoint area $\left(\mathrm{m}^{2}\right)$ & 242 & 326.3 & 29.9 & 294 & 369 \\
\hline HOPR $(\mathrm{m})$ & 242 & 149.5 & 13.3 & 130 & 229 \\
\hline HOD $(\mathrm{m})$ & 253,871 & 174.9 & 96.9 & 8.4 & 521.2 \\
\hline Ratio between HOD and HOPR $(\%)$ & 253,871 & 112.1 & 57.8 & 5.7 & 297.9 \\
\hline Planned draw rates (tpd/m $\left.{ }^{2}\right)$ & 2,904 & 0.54 & 0.27 & 0.06 & 1.5 \\
\hline Hang-up frequency (ton/hang-up) & 8,274 & 943 & 728 & 74 & 10,683 \\
\hline
\end{tabular}

\section{$3 \quad$ Method}

\subsection{Drawpoint availability model}

This research proposes a model for assessing drawpoint availability considering hang-up frequency and secondary breaking requirement to meet short-term production plans, as shown in (1).

$$
D A=\frac{t_{p}}{t_{p}+t_{D U}+t_{S B}+t_{R P B}}(\%)
$$

where

$D A=$ corresponds to drawpoint availability measured.

$t_{p} \quad=$ indicates the time of planned draw at drawpoints.

$t_{D U}=$ refers to the drawpoint unavailable time for draw because of hang-up occurrence.

$t_{S V}=$ indicates the time of secondary breaking requirement to remove a hang-up.

$t_{R P B}=$ defines the re-entry time post blasting after a secondary breaking.

Equation (2) controls the maximal drawpoint productivity per planned period as hang-up frequency is incorporated into the model.

$$
t_{p}=\frac{H U_{f}}{D R \times D_{a}}
$$

where

$$
\begin{aligned}
& H U_{f}=\text { indicates hang-up frequency measured in ton/hang-up. } \\
& D R=\text { defines the planned draw rates in ton } / \mathrm{m}^{2} \text { day. } \\
& D_{a}=\text { refers to the drawpoint area in } \mathrm{m}^{2} .
\end{aligned}
$$

\subsection{Drawpoint data categorization}

Drawpoints from Diablo Regimiento and Esmeralda mines are classified according to the geotechnical zones of the study area. In addition, three independent domains are considered for each geotechnical zone in order to determine the influence of the draw of the primary rock column on drawpoint availability. These domains are cave propagation, cave production, and cave over-extraction. Cave propagation is defined for values between $5 \%$ and $30 \%$ draw of the primary rock column, and takes into account 
the initial cave growth and its fragmentation process, where low hang-up frequency is expected. Cave production domain considers drawing ore at relaxed cave columns (once cave subsidence reaches upper mines). This domain contains information in the range $30 \%$ to $100 \%$ draw of the primary rock column, where hang-up frequency is supposed to be increased by effect of secondary fragmentation as the draw column rises. Finally, cave over-extraction domain includes data larger than $100 \%$ draw of the primary rock column. In this domain, the effect of the content of fine material is expected to increase hang-up frequency as compared with the previous domains.

\subsection{Computing variables}

Given the large amount of data gathered from the study area, most of the variables in equation (1) and equation (2) provide a set of values capable of providing statistics and allowing for the construction of histograms. Such an analysis is carried out for hang-up frequency $\left(H U_{f}\right)$, drawpoint unavailable time $\left(t_{D U}\right)$ and secondary breaking requirement $\left(t_{S B}\right)$. In contrast, the re-entry time post blasting $\left(t_{R P B}\right)$ was set at 15 minutes since it is an established time throughout cave operating at the study case. Firstly, Grubbs' outlier test was performed for each variable to determine significant outliers within the database, and then, analysis of variance (ANOVA) was applied to test relevant mean differences between geotechnical zones in each cave domain. Probability density functions are therefore assessed based on the histograms of each variable by using the Kolmogorov-Smirnov goodness of fit test at critical value ( $p$-value) 0.05 , quantifying the difference between the empirical distribution function of the data and the cumulative distribution function of numerous known distributions. Subsequently, Monte Carlo simulation technique was applied alongside each probability distribution to compute equation (1) and equation (2), generating a stochastic approach for drawpoint availability. Random values range from zero to one were generated to obtain values of drawpoint availability distribution for each domain and geotechnical zone. Finally, the use of planned draw rates, drawpoints area, and drawpoints availability results in an estimation of the expected ore drawn during short-term cave planning.

Note that this methodology is applied to those drawpoints classified by the corresponding geotechnical zone and cave domain.

\section{$4 \quad$ Results and discussion}

\subsection{Hang-up frequency analysis}

The measurement unit of hang-up frequency is the ore drawn between two consecutive observations of hang-ups at a drawpoint according to the secondary breaking database. The hang-up phenomenon is analysed considering the three domains related to the draw of primary rock column and the geotechnical zoning in the study area. In order to test whether the three domains means are equal among geotechnical zones, ANOVA is used with a null hypothesis stating that, for each cave domain, all the geotechnical zones have the same mean. At critical value 0.05 , there are grounds to reject the null hypothesis, and hence, each group of hang-up frequency is different between them.

Afterward, the Kolmogorov-Smirnov goodness of fit tests indicate that hang-up frequency for the three domains and all geotechnical zones follow a lognormal distribution at $p$-value 0.05 . Other probability distributions (e.g., Weibull and exponential) were tested, without exhibiting better statistical results. The lognormal density functions are presented from Figure 3 to Figure 5, and their statistics are summarised in Table 3. 


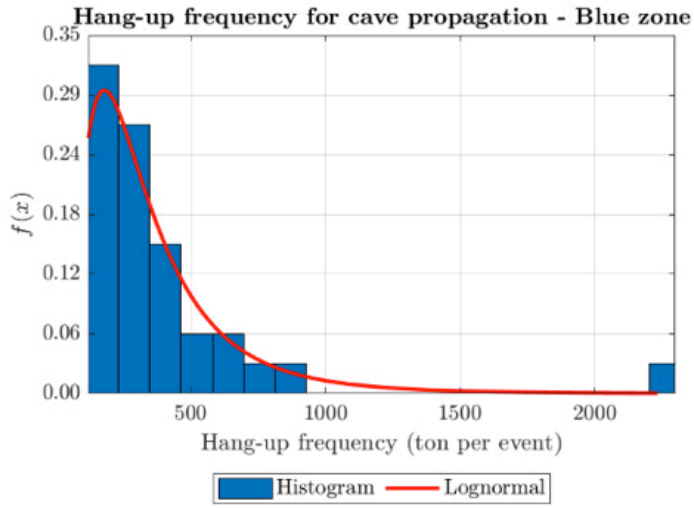

(a)

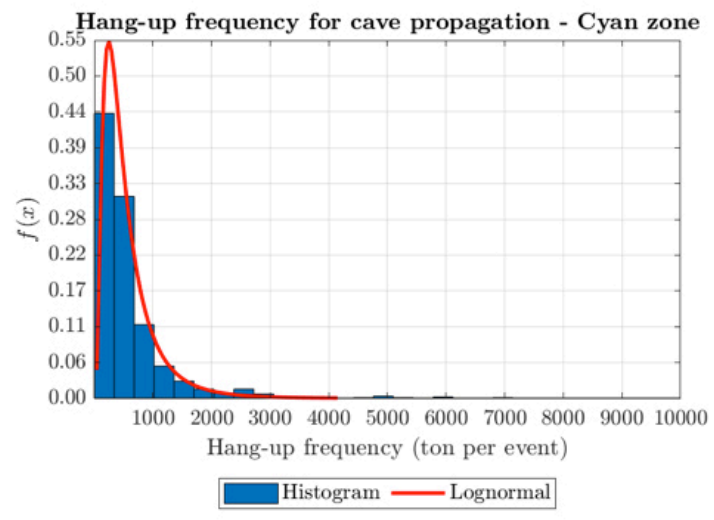

(c)

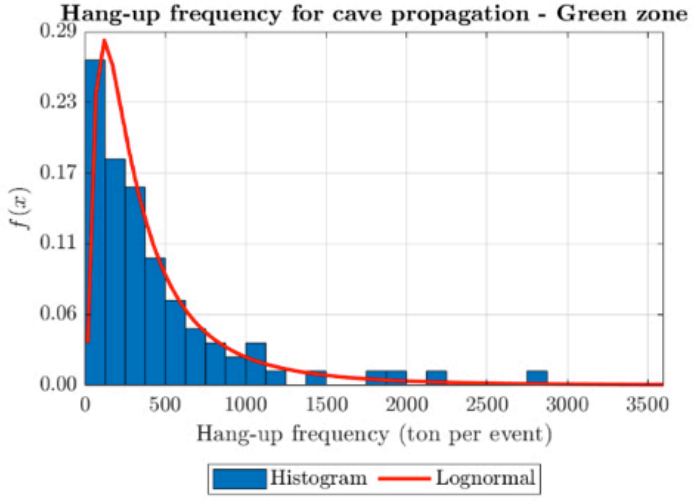

(b)

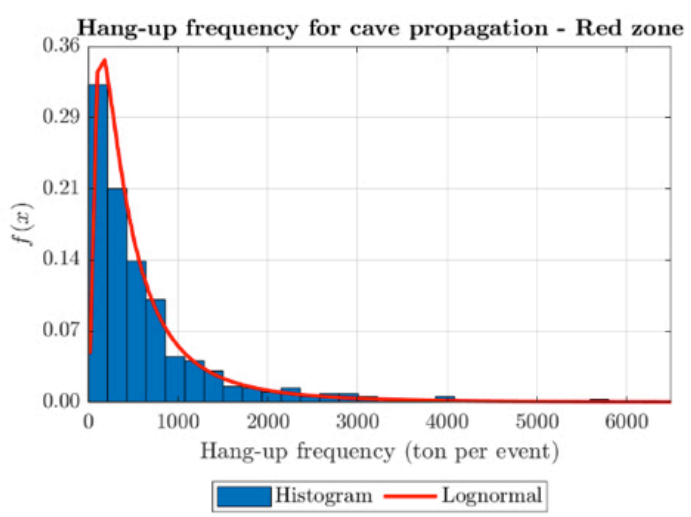

(d)

Figure 3 Histograms and probability density functions of hang-up frequency for cave propagation domain. (a) Blue zone (b) green zone (c) cyan zone and (d) red zone

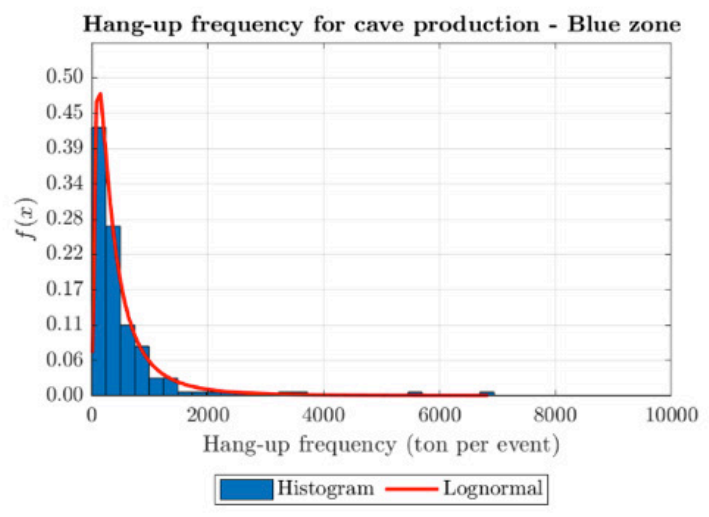

(a)

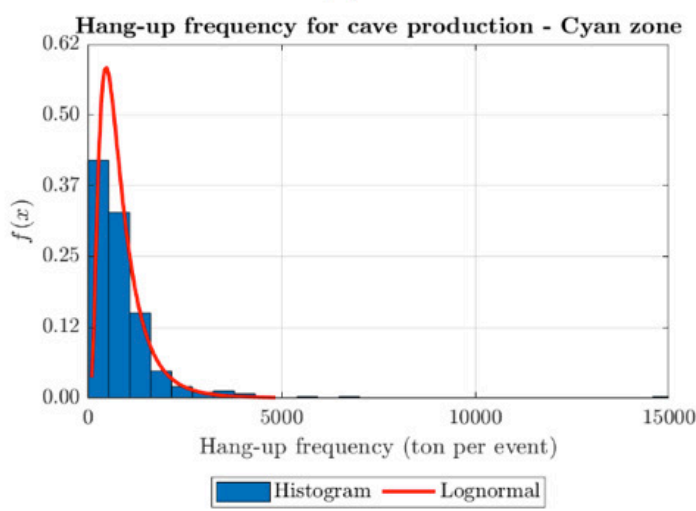

(c)

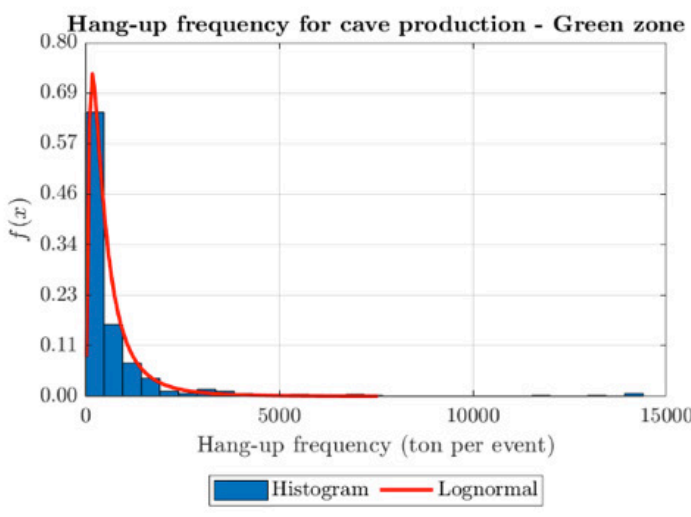

(b)

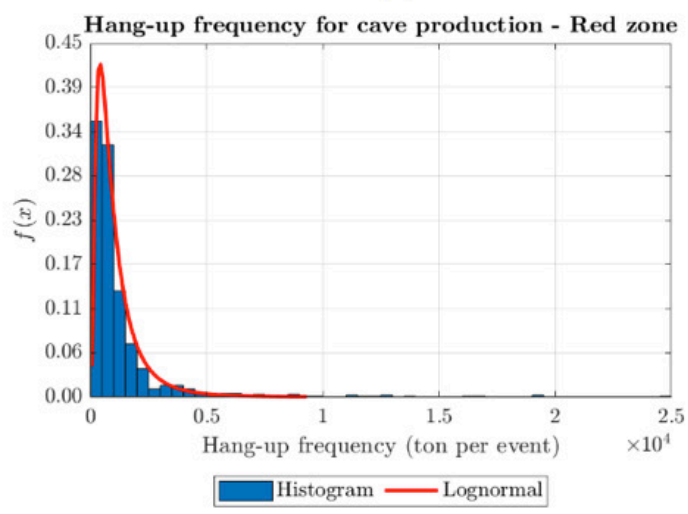

(d)

Figure 4 Histograms and probability density functions of hang-up frequency for cave production. (a) Blue zone (b) green zone (c) cyan zone and (d) red zone 


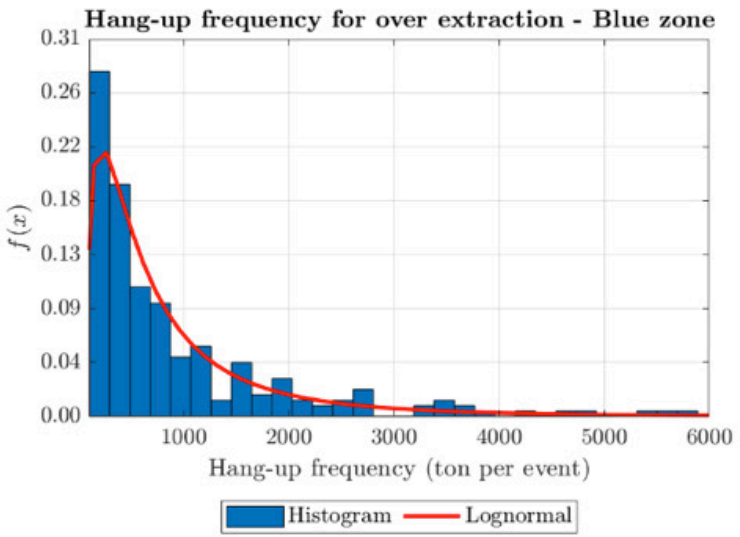

(a)

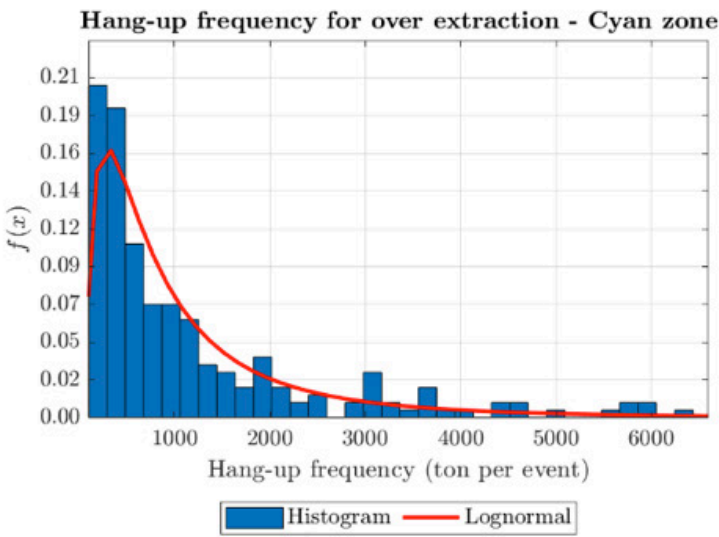

(c)

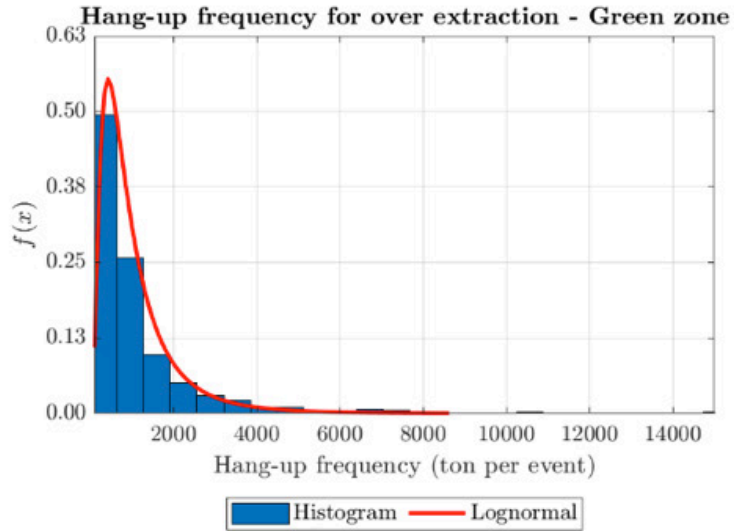

(b)

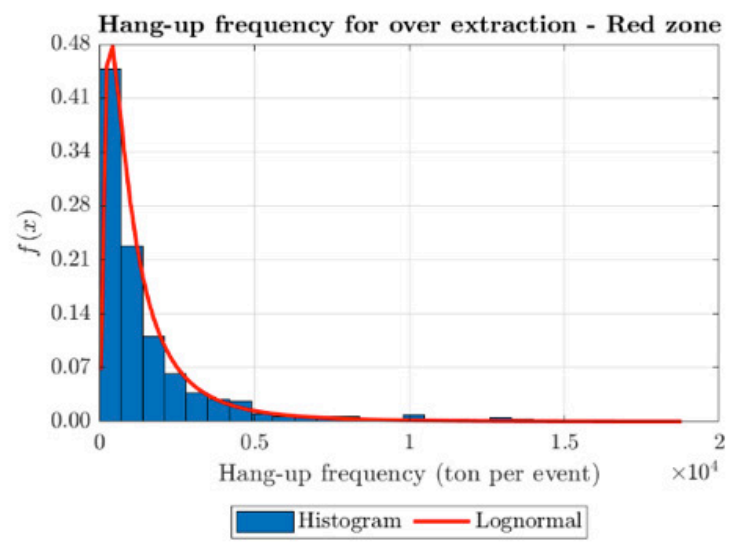

(d)

Figure 5 Histograms and probability density functions of hang-up frequency for cave over-extraction. (a) Blue zone (b) green zone (c) cyan zone and (d) red zone

Table 3 Summary of main lognormal distribution statistics of the hang-up analysis

\begin{tabular}{|c|c|c|c|c|c|c|c|c|c|c|}
\hline Domain & $\begin{array}{l}\text { Lognormal } \\
\text { statistics }\end{array}$ & $\begin{array}{l}\text { Blue } \\
\text { zone }\end{array}$ & $\begin{array}{l}\text { Green } \\
\text { zone }\end{array}$ & $\begin{array}{l}\text { Cyan } \\
\text { zone }\end{array}$ & $\begin{array}{l}\text { Red } \\
\text { zone }\end{array}$ & Statistics & $\begin{array}{l}\text { Blue } \\
\text { zone }\end{array}$ & $\begin{array}{c}\text { Green } \\
\text { zone }\end{array}$ & $\begin{array}{l}\text { Cyan } \\
\text { zone }\end{array}$ & $\begin{array}{l}\text { Red } \\
\text { zone }\end{array}$ \\
\hline \multirow{2}{*}{$\begin{array}{c}\text { Cave } \\
\text { propagation }\end{array}$} & $\sigma$ & 0.68 & 0.95 & 0.76 & 0.99 & Mean & 358 & 460 & 580 & 672 \\
\hline & $\mu$ & 5.65 & 5.68 & 6.07 & 6.02 & Std. & 273 & 437 & 470 & 667 \\
\hline \multirow[t]{2}{*}{ Cave production } & $\sigma$ & 0.97 & 0.95 & 0.64 & 0.82 & Mean & 518 & 681 & 869 & 1,120 \\
\hline & $\mu$ & 5.78 & 6.07 & 6.56 & 6.69 & Std. & 503 & 650 & 647 & 948 \\
\hline \multirow{2}{*}{$\begin{array}{l}\text { Cave over- } \\
\text { extraction }\end{array}$} & $\sigma$ & 0.99 & 0.79 & 0.98 & 0.99 & Mean & 947 & 1,090 & 1,232 & 1,549 \\
\hline & $\mu$ & 6.36 & 6.68 & 6.63 & 6.85 & Std. & 946 & 905 & 1,213 & 1,544 \\
\hline
\end{tabular}

Based on Table 3, an upward trend for each cave domain indicates that hang-up frequency increases with better rock cavability. Similar results were obtained in previous studies in other sectors of El Teniente mine, where the percentage of oversize reduces as the draw of primary rock column increases (Brzovic et al. 2016). Furthermore, this effect is remarkably noted when comparing the significant increase of hangup frequency in each geotechnical zone at different cave domains (effect of secondary fragmentation trough the cave column). Thus, the use of cave domains reveals the importance of ore size distribution and its direct impact on hang-up occurrence as the increase of hang-up frequency provides a better flowability of caved ore (Castro et al. 2016). 


\subsection{Hang-ups duration analysis}

Hang-up duration is the number of hours between two consecutive secondary breaking activities. This variable is studied at each cave domain and geotechnical zone. ANOVA is applied to test if the three domains means are equal among geotechnical zones, which is considered as the null hypothesis. At critical value 0.05 , there is strong evidence for accepting the null hypothesis, and therefore, no significant differences are observed among geotechnical zones means in each cave domain. Subsequently, hangups duration for all cave groups follows a lognormal distribution according to the Kolmogorov-Smirnov goodness of fit tests at $p$-value 0.05 . The results of hang-ups duration analysis are presented in Figure 6 and summarized in Table 4.

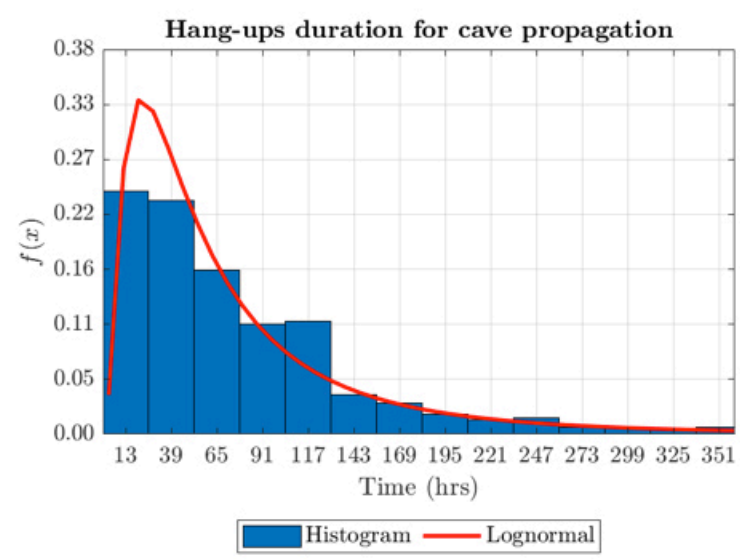

(a)

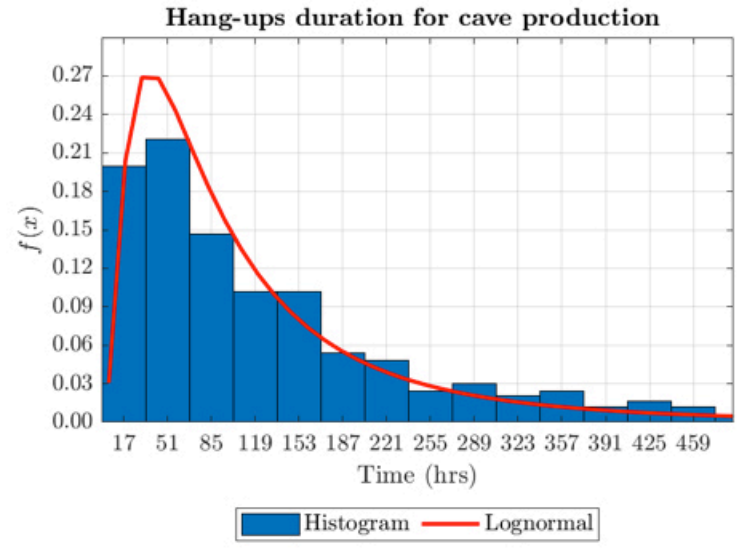

(b)

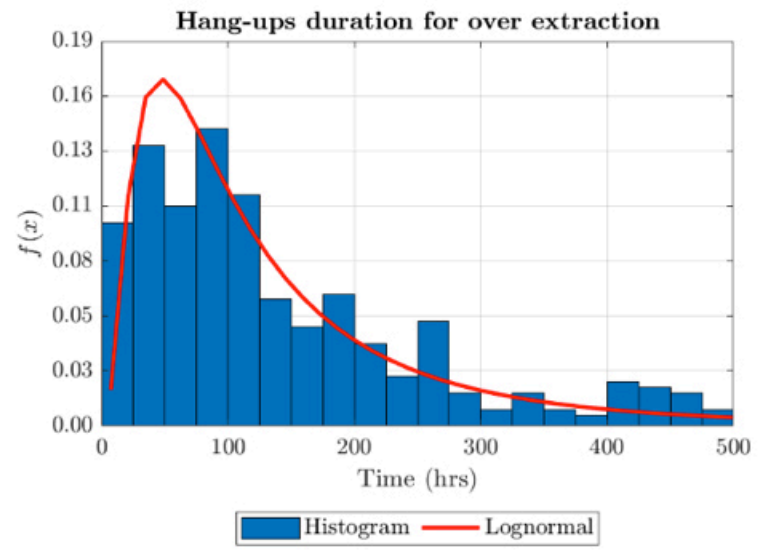

(c)

Figure 6 Histograms and probability density functions of hang-ups duration. (a) Cave propagation (b) cave production and (c) cave over-extraction

Table 4 Summary of main lognormal distribution statistics of the hang-ups duration

\begin{tabular}{|c|c|c|c|c|}
\hline \multirow{2}{*}{ Domain } & \multicolumn{2}{|c|}{$\begin{array}{c}\text { Lognormal } \\
\text { statistics }\end{array}$} & \multicolumn{2}{c|}{ Statistics } \\
\cline { 2 - 5 } & $\boldsymbol{\sigma}$ & $\boldsymbol{\mu}$ & Mean (hrs) & Std. (hrs) \\
\hline Cave propagation & 0.93 & 3.95 & 80 & 74 \\
\hline Cave production & 0.91 & 4.43 & 127 & 116 \\
\hline Cave over-extraction & 0.93 & 4.56 & 146 & 147 \\
\hline
\end{tabular}

Generally, hang-ups duration tends to increase according to the increment of draw of the primary rock column, which may be explained by two main effects. First, as noted in Table 3, low hang-up frequency is expected in the cave propagation domain, meaning that a large quantity of hang-ups occur in a short period during ore drawing. In addition to this, drawpoints in the cave propagation domain have draw 
priority in order to maintain cave growth, cave angles, and cave-front orientation, generating intensive secondary breaking in this area. For the other domains, the increase of hang-up frequency implies the necessity for more operating time to generate a cluster of drawpoints with hang-ups, and also, there is typically less extraction priority for drawpoints with $>100 \%$ draw of primary rock column because of the low ore grades and the presence of dilution.

\subsection{Secondary breaking requirement}

Data were gathered level by measuring the time that secondary breaking crews required to drill and blast hang-ups at drawpoints. These measures were carried out throughout two months, providing limited sample data to test numerous probability density functions. Therefore, a triangular distribution is employed to estimate the variable representation.

The triangular distribution considers the lower limit as $1.75 \mathrm{hrs}$, the upper limit as $4 \mathrm{hrs}$, and the mode as 2.5 hrs.

\subsection{Drawpoint availability}

The drawpoint availability model proposed in equation (1) was carried out using the Monte Carlo simulation method and a probability associated with lognormal distributions, providing probability density functions for each cave domain and geotechnical zone as depicted from Figure 7 to Figure 9. The KolmogorovSmirnov goodness of fit tests are performed to assess drawpoint availability distributions of each group at critical value 0.05 . The results are statistically significant and indicate that all the analysed groups follow a normal distribution, whose parameters are summarised in Table 5.

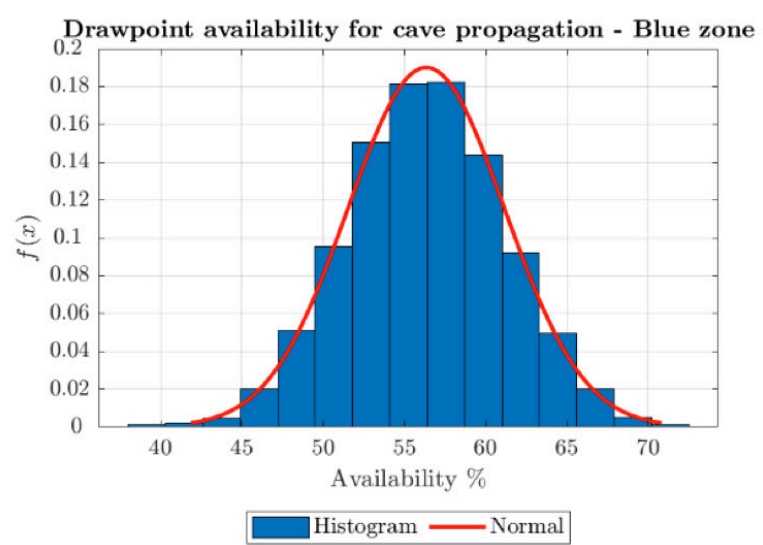

(a)

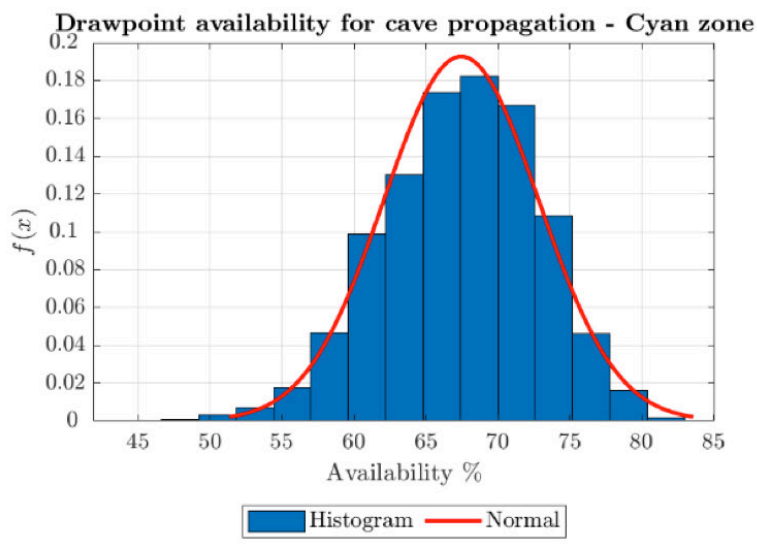

(c)

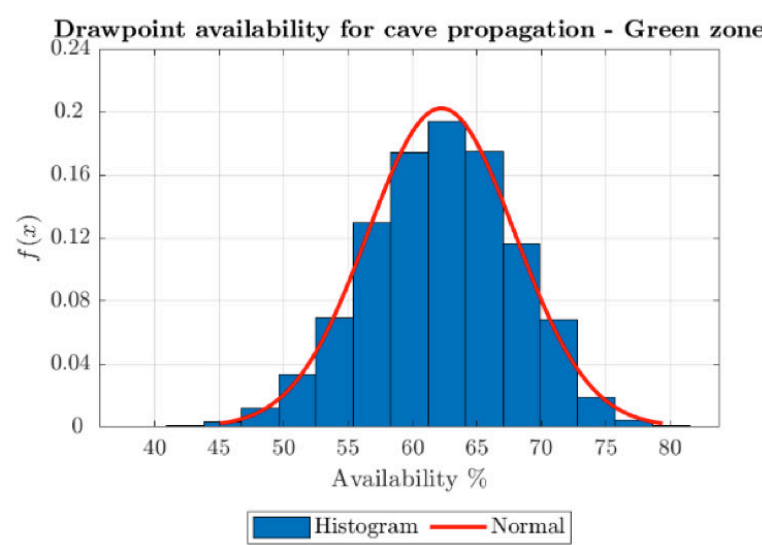

(b)

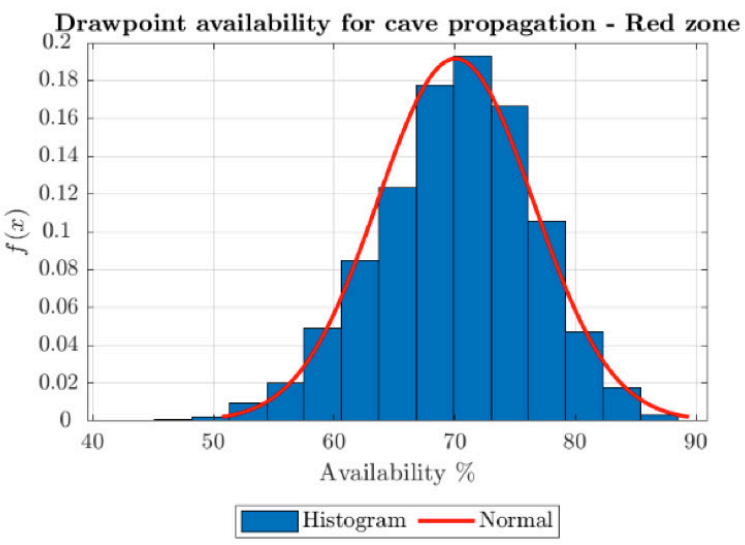

(d)

Figure 7 Histograms and probability density functions of drawpoint availability for cave propagation domain. (a) Blue zone (b) green zone (c) cyan zone and (d) red zone 


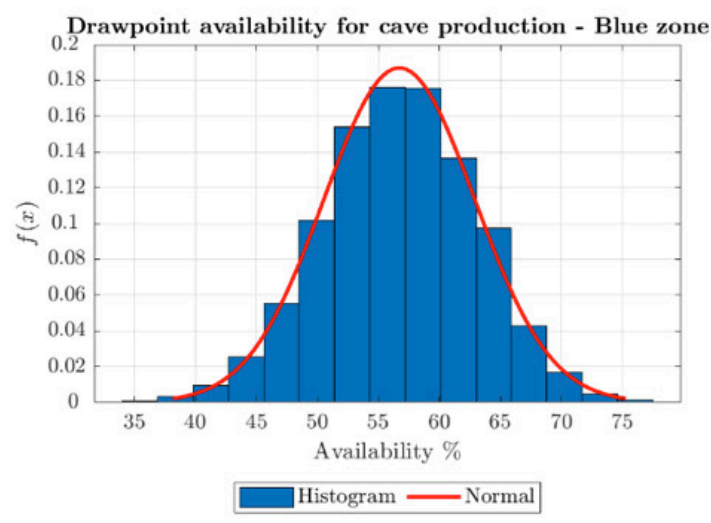

(a)

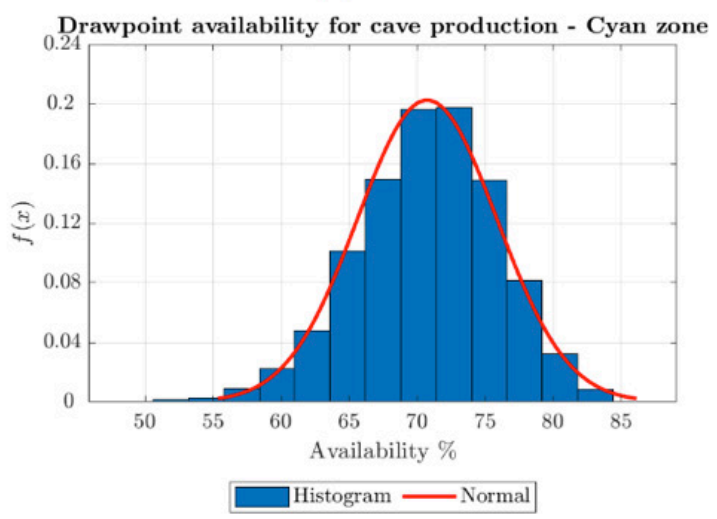

(c)

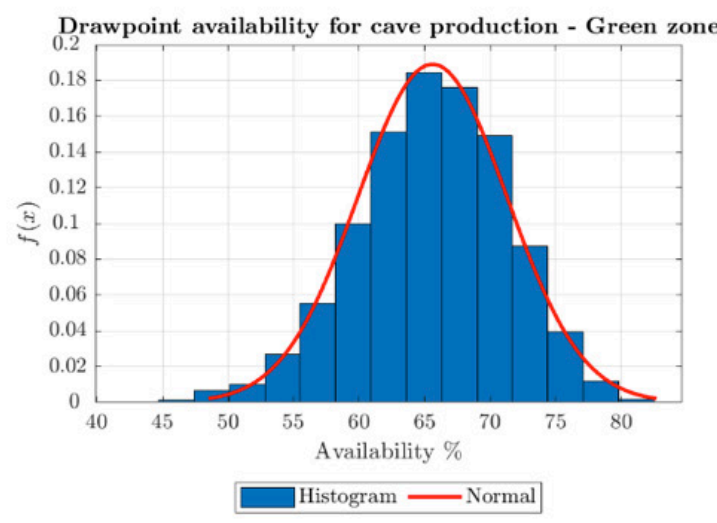

(b)

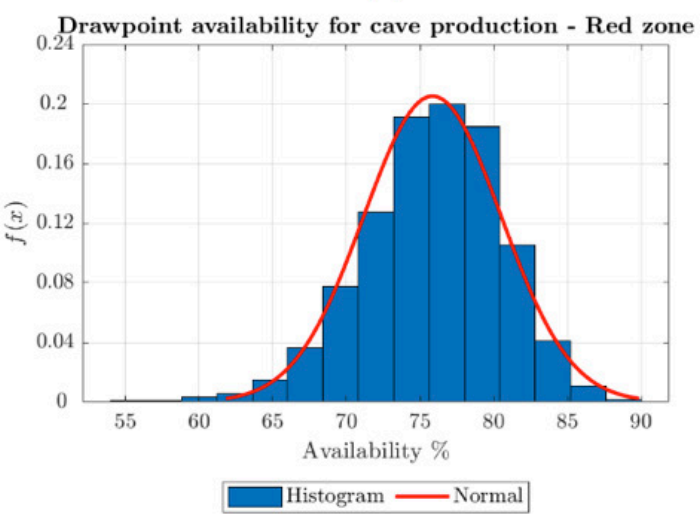

(d)

Figure 8 Histograms and probability density functions of drawpoint availability for cave production domain. (a) Blue zone (b) green zone (c) cyan zone and (d) red zone

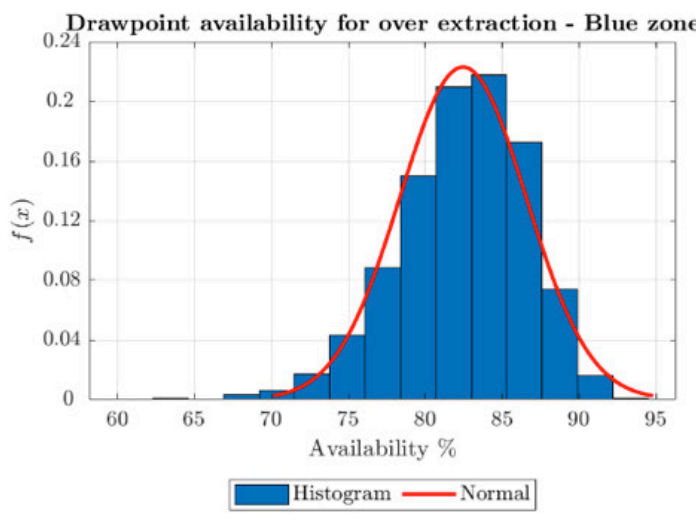

(a)

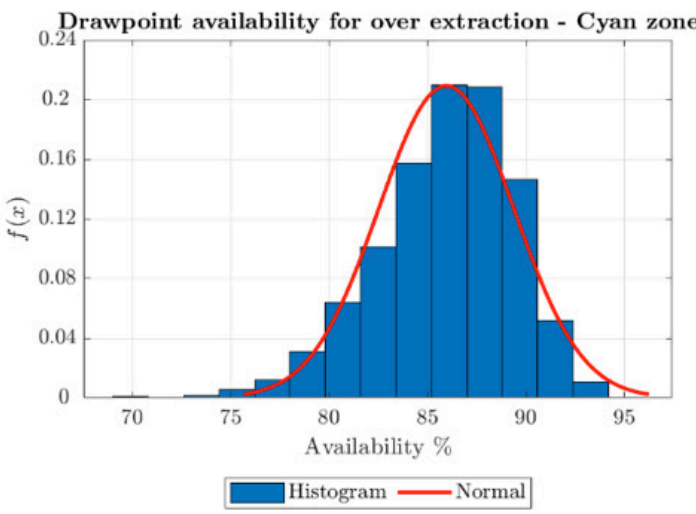

(c)

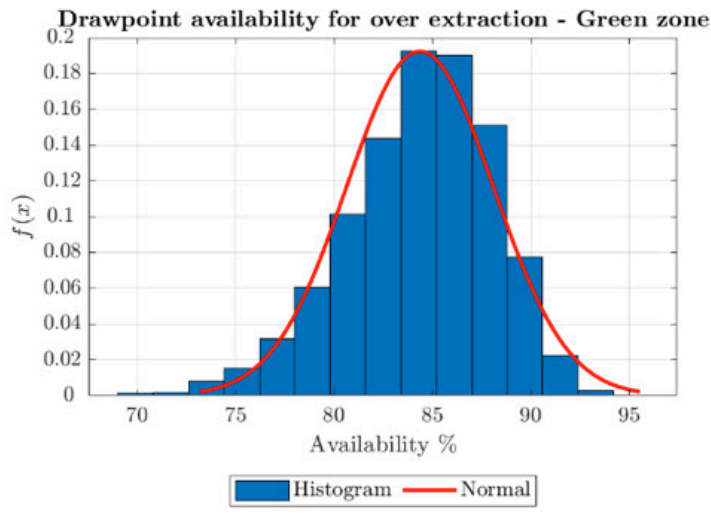

(b)

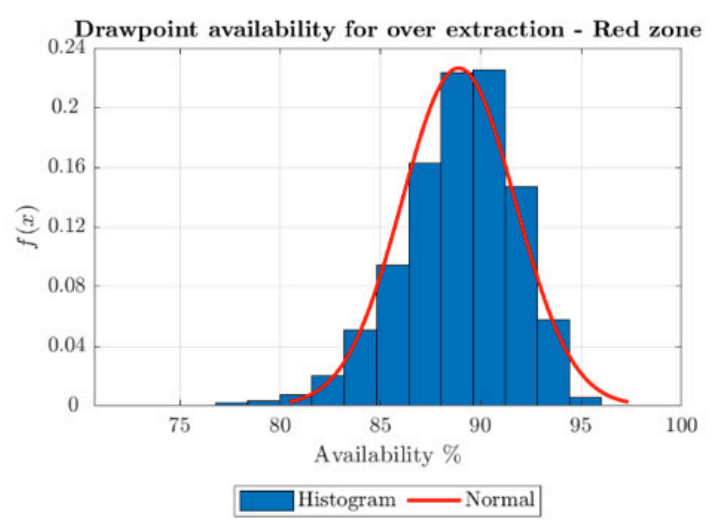

(d)

Figure 9 Histograms and probability density functions of drawpoint availability for over-extraction domain. (a) Blue zone (b) green zone (c) cyan zone and (d) red zone 
Table 5 Summary of main normal distribution statistics of drawpoint availability

\begin{tabular}{|c|c|c|c|c|c|}
\hline Domain & Statistics & Blue zone & Green zone & Cyan zone & Red zone \\
\hline \multirow{2}{*}{ Cave propagation } & Mean & $56 \%$ & $62 \%$ & $67 \%$ & $70 \%$ \\
\cline { 2 - 6 } & Std. & $5 \%$ & $6 \%$ & $5 \%$ & $6 \%$ \\
\hline \multirow{2}{*}{ Cave production } & Mean & $59 \%$ & $66 \%$ & $72 \%$ & $77 \%$ \\
\cline { 2 - 6 } & Std. & $6 \%$ & $6 \%$ & $5 \%$ & $5 \%$ \\
\hline \multirow{2}{*}{ Cave over-extraction } & Mean & $82 \%$ & $84 \%$ & $86 \%$ & $89 \%$ \\
\cline { 2 - 6 } & Std. & $4 \%$ & $4 \%$ & $3 \%$ & $3 \%$ \\
\hline
\end{tabular}

It is important to note that different draw rates were considered in equation (2). Based on short-term cave plans during 2019, average draw rates of $0.7 \mathrm{tpd} / \mathrm{m}^{2}$ are used in the cave propagation domain, $0.9 \mathrm{tpd} /$ $\mathrm{m}^{2}$ in the cave production domain, and $0.5 \mathrm{tpd} / \mathrm{m}^{2}$ in the over-extraction domain.

As expected from previous results, geotechnical characteristics of in situ rock have a direct impact on drawpoint available for cave mines. In terms of rock mass quality, drawpoint availability slightly increases as the in situ primary rock is more cavable from cave propagation to cave over-extraction domain. This effect is due to the raise of hang-hang frequency, while the mean draw rates at drawpoints used in equation (2) remain constant.

On the other hand, drawpoint availability greatly increases from cave production to cave over-extraction domain, but the same effect is not observed when passing from cave propagation and cave production. The former effect is explained by the increase of hang-up frequency for all geotechnical zones combined with the decrease of average draw rates for the over-extraction domain. Time of planned draw at drawpoints increases according to equation (2), and so drawpoint availability directly raises. The latter effect is primarily induced by the increment of average draw rates for the cave production domain even though hang-up frequency also increases, but to a lesser extent as observed in equation (2). Therefore, not only does hang-up frequency impact on drawpoint availability, but also draw rates play a more significant role in its assessment than previously noticed.

\subsection{Application of drawpoint availability modelling for short-term planning}

Once the drawpoint availability is estimated for each cave domain and geotechnical zone, a prediction of the ore tonnage expected to be monthly drawn during 2019 is carried out with all the parameters required to compute each drawpoint production assessment. To this end, equation (3) is used to predict the ore tonnage through this methodology.

$$
P T=D R \times D_{a} \times D A
$$

where,

$$
\begin{aligned}
& P T=\text { corresponds to the predicted tonnage in ton. } \\
& D R=\text { refers to the planned draw rates measured in ton } / \mathrm{m}^{2} \text { day. } \\
& D_{a}=\text { indicates the drawpoint area in } \mathrm{m}^{2} \\
& D A=\text { defines the drawpoint availability estimated in percentage. }
\end{aligned}
$$

As a result, Figure 10a shows the predicted tonnage and real ore drawn at the study area on a monthly basis. In addition, this figure includes minimum and maximum predicted tonnages based on the standard deviation of drawpoint availability for each cave domain and geotechnical zone presented in Table 5. 


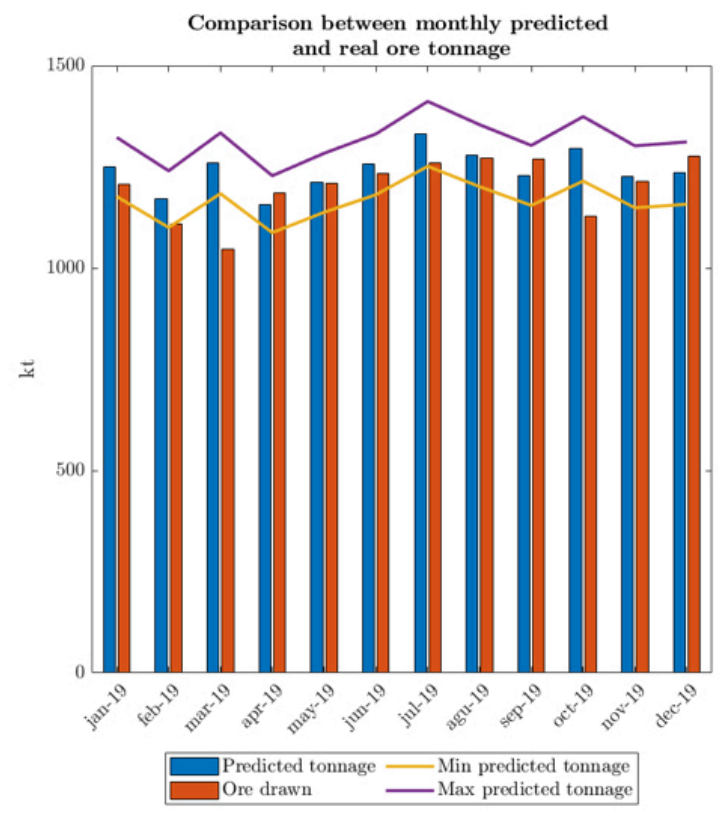

(a)

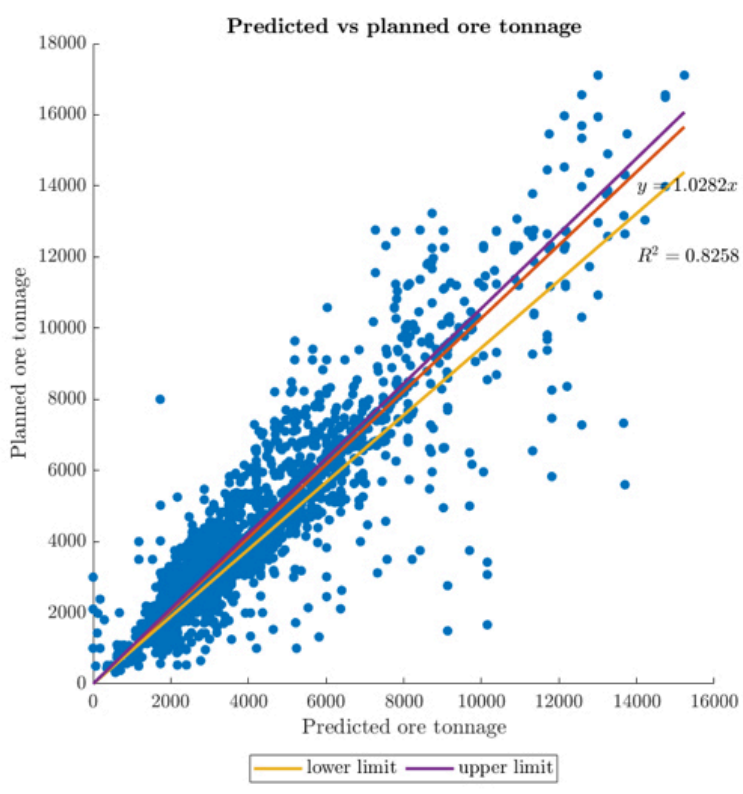

(b)

Figure 10 (a) Monthly predicted tonnage and real ore drawn during 2019 and (b) scatter plot of monthly predicted versus planned ore tonnage in 2019

Predicted tonnages are considerably similar to the ore drawn, where monthly ore drawn are in the minimum and maximum range during most of the studied period. Furthermore, the difference between the ore tonnages predicted through the model and real drawn is 3.4 per cent average. Accordingly, this result implies that the drawpoint availability model may be applied to estimate the monthly ore tonnage in short-term cave plans properly. In addition to this, Figure 10b exhibits a comparison of predicted and planned ore tonnages in 2019, indicating that current planning process leads to roughly 2.8 per cent more optimistic estimates of monthly ore tonnage. Hence, this study provides a method to incorporate the drawpoint availability uncertainty into the short-term cave planning, and also, to generate reachable monthly cave production goals.

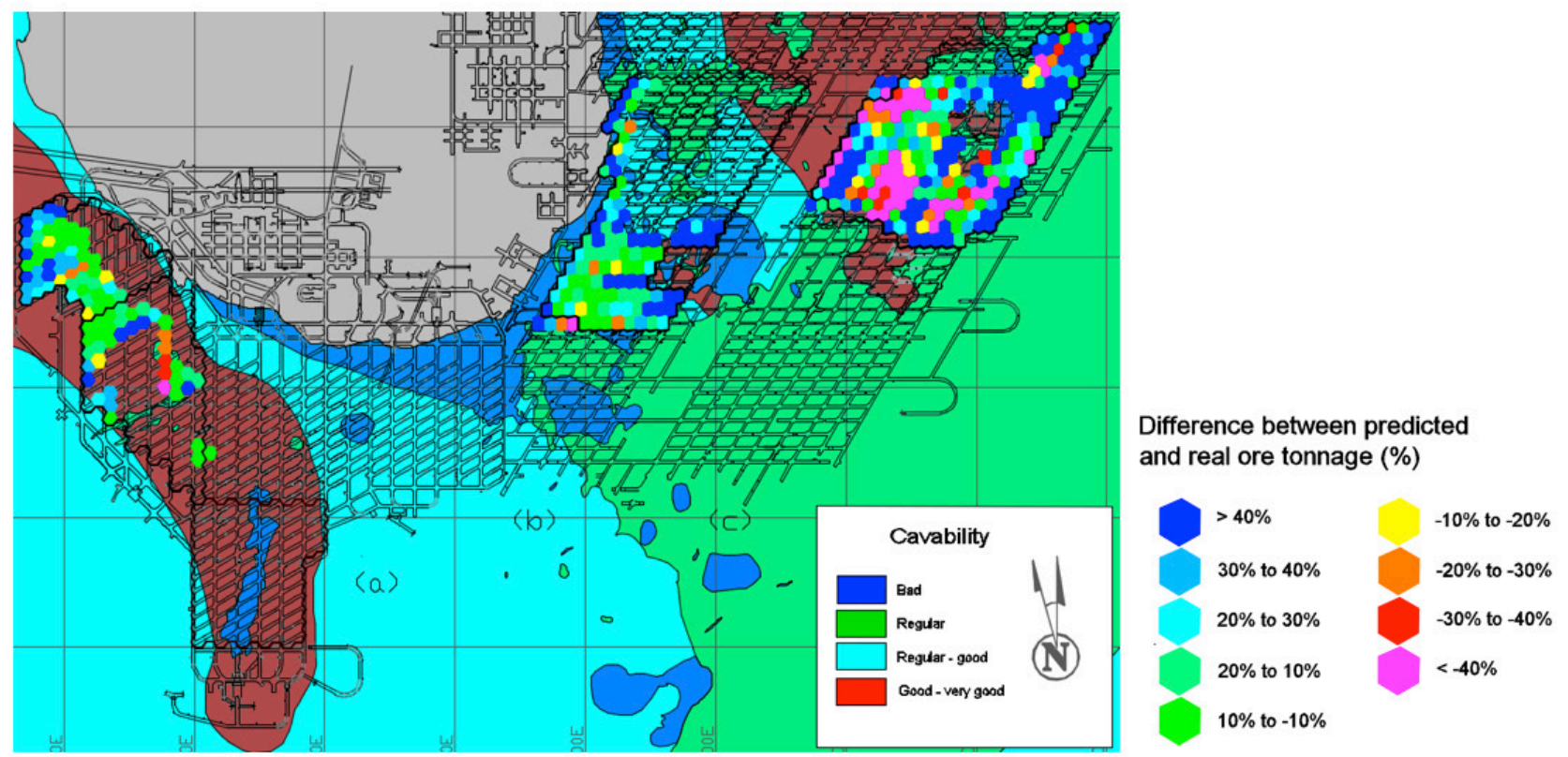

Figure 11 Heat map of the studied area indicating the differences between predicted and real ore tonnage in 2019. (a) Diablo Regimiento and (b) Esmeralda's Block-1 and (c) Block-2 mines

The predicted capacity of the model for each drawpoint under study is examined through a heat map (Figure 11). The colour coding denotes the percentage difference between predicted and real ore tonnage. For instance, dark-blue coloured solids indicate that the predicted tonnage is 40 per cent greater than 
the real ore drawn, while pink-coloured solids signify predicted tonnage 40 per cent smaller than real ore drawn. As noted, most of the drawpoints exhibit green coloured solids, meaning that the predicted results have differences ranging from ten to minus ten per cent of the real ore tonnage. However, highly variable results are obtained in Esmeralda's Block 2 cave mine owing to numerous production level damages and operational issues during 2019 described as follows:

- In the north-eastern area, pink-coloured drawpoints were extracted at draw rates higher than planned rates since the occurrence of high drawpoint hang-up frequency. This operational decision allowed for dealing with the lack of ore available for draw in southern drawpoints of the same extraction drift due to gravity slabbing and wedge failure (blue-coloured drawpoints). Hence, monthly production goals in Esmeralda's Block 2 cave mine were mostly achieved throughout 2019.

- In the southern zone, pink-coloured drawpoints registered high draw rates during 2019 to regain the production loss caused by a series of structural collapses in the surrounding area (bluecoloured drawpoints).

- In the western side of the production level, blue-coloured drawpoints were extracted at draw rates lower than planned rates because of two main issues. First, this area dealt with continual operational interferences as it was considered as a route for mine development crews during 2019. Subsequently, several development activities were performed without considering planned drawpoints availability in monthly short-term plans, generating significant production losses. Second, these drawpoints suffered from low hang-up frequency and difficulties in cave propagation through the ore column, leading to fewer production rates than expected.

\section{Conclusions}

The goal of this study was to define a model for assessing the drawpoint availability uncertainty in shortterm cave planning. The proposed modelling is developed utilising data gathered at El Teniente mine, and it principally depends on hang-up phenomenon and secondary breaking activities. The results indicate that the model is able to suitably estimate the monthly ore tonnage with an acceptable 3.4 per cent average error during a year. Moreover, the use of cave domains and geotechnical to categorise mine data may be of great importance when analysing the effect of hang-up frequency on drawpoint availability. This is consistent with the fact that for less competent rock columns or high draw of primary column, more cave ore production is expected as a result of the fine fragmentation within the cave column. Finally, this article enables the incorporation of drawpoint availability uncertainty into short-term cave planning, allowing the generation of more achievable monthly production goals.

Nevertheless, since the drawpoint availability model presented herein is based on hang-up frequency and secondary breaking, further research could improve cave production performance. Hang-up frequency ought to be addressed in less cavable rock mass in order to significantly decrease the proportion of oversize at drawpoints. Therefore, studies may be focused on novel strategies (e.g., optimizing burden fractures in hydraulic fracturing, new confined blasting designs) to enhance fragmentation within the cave column. Additionally, secondary breaking presents a relevant bottleneck in cave mining production, as it is a time intensive process. Research should be conducted on assessing the number of secondary breaking activities required for a given daily production rate or incorporating novel technology and techniques to optimise the operating time.

\section{Acknowledgement}

The authors gratefully acknowledge El Teniente mine of Codelco-Chile for supporting the research and allowing this article to be published. We would also wish to thank our colleagues Kenji Basaure, Roberto González and Paulina Schachter for their insight and contribution to the hang-up frequency analysis. 


\section{References}

Brzovic, A, Vallejos, J, Arancibia, E, Burgos, L, Delonca, A, Gaete, M \& Barrera, V 2016, 'Analysis and modelling of the fragmentation process - Case studies at El Teniente mine', in C Carr \& G Chitombo (eds), Proceedings of MassMin 2016, Sydney, pp. 305-310.

Brzovic, A \& Schachter, P 2013, 'Rock mass geotechnical characterization based on the weak stockwork veins at the El Teniente Mine', in Proceedings of the Third International Seminar on Geology for the Mining Industry, Santiago.

Brzovic, A \& Villaescusa, E 2007, 'Rock mass characterization and assessment of block-forming geological discontinuities during caving of primary copper ore at the El Teniente Mine, Chile', International Journal of Rock Mechanics and Mining Sciences, vol. 44, no. 4, pp. 565-583.

Castro, R, Gómez, R \& Hekmat, A 2016, 'Experimental quantification of hang-up for block caving applications', International Journal of Rock Mechanics \& Mining Sciences, vol. 85, pp. 1-9.

Chitombo, GP 2010, 'Cave mining - 16 years after Laubscher's 1994 paper 'Cave mining - state of the art", in Proceedings of the Second International Symposium on Block and Sublevel Caving, ed. Y. Potvin, ACG, Perth, pp. 45-61.

Dershowitz, WS \& Einstein HH 1988, 'Characterizing rock joint geometry with joint system models', Rock Mechanics and Rock Engineering, Vol. 21, no. 1, pp. 21-51.

Dirkx, R, Kazakidis, V \& Dimitrakopoulos, R 2019, 'Stochastic optimisation of long-term block cave scheduling with hang-up and grade uncertainty', International Journal of Mining, Reclamation and Environment, vol. 33, no. 6, pp. $371-388$.

Laubscher, DH 1994, 'Cave mining - the state of the art', The Journal of The South African Institute of Mining and Metallurgy, pp. 279-293.

Ngidi, S \& Boshoff, P 2011, 'Cave management and secondary breaking practices at Palabora Mining Company', in Proceeding of The Sixth Southern African Base Metals conference, SAIMM, Phalaborwa, pp. 209-220.

Ngidi, SN \& Pretorius, DD 2011, 'Impact of poor fragmentation on cave management', in Proceeding of The Sixth Southern African Base Metals conference, SAIMM, Phalaborwa, pp. 111-121.

Ngidi, S \& Boshoff, P 2007, 'Cave management and secondary breaking practices at Palabora Mining Company', The Journal of The South African Institute of Mining and Metallurgy, pp. 783-789.

Rubio E \& Troncoso S 2008, 'Discrete events simulation to integrate operational interruption events in block cave production scheduling', in Third International Conference on Mining Innovation, Santiago.

Rubio, E \& Dunbar, WS 2005, 'Integrating uncertainty in block cave production scheduling', in Proceedings of the 32nd International Symposium on the Application of Computers and Operations Research in the Mineral Industry (APCOM), ed. S. Dessureault, R. Ganguli, V. Kecojevic, J. Girard-Dwyer, Tucson, pp. 635-642.

Viera, E \& Diez E 2014, 'Analysis of hangup frequency in Bloque 1-2, Esmeralda Sur mine', in Proceedings of the Third International Symposium on Block and Sublevel Caving, ed. R. Castro, University of Chile, Santiago, pp. 138-145. 